\title{
Comparison of entrance surface air kerma measurement with MTS-N (LiF: Mg, Ti) chips with a kilovoltage X-ray source
}

\author{
Akintayo Daniel Omojola, M.Sc. ${ }^{(1)}$ \\ Samuel Olaolu Adeneye, Ph.D. ${ }^{(2)}$ \\ Michael Onoriode Akpochafor, Ph.D. ${ }^{(2)}$ \\ Isiaka Olusola Akala, M.Sc. ${ }^{(3)}$ \\ Azuka Anthonio Agboje, M.Sc. ${ }^{(1)}$ \\ From ${ }^{(1)}$ Department of Radiology, Medical Physics Unit, Federal Medical Centre Asaba, \\ Delta State, Nigeria. \\ ${ }^{(2)}$ Department of Radiation Biology, Radiotherapy and Radiodiagnosis, \\ College of Medicine, University of Lagos, Lagos State, Nigeria. \\ ${ }^{(3)}$ Department of Radiology, Lagos University Teaching Hospital, Ikeja, Lagos, \\ Lagos State, Nigeria. \\ Address correspondence to A.D.O. (e-mail: akintayo.omojola@fmcasaba.org)
}

Received 30 November 2020; revised 10 February 2021; accepted 18 March 2021

doi:10.46475/aseanjr.v22i1.96

\section{Abstract}

Objective: Radiation detectors are key components that ensure the accuracy and performances of dosimetry equipment. The study is aimed to compare the mean entrance surface air kerma (ESAK) between a DCT-100mm ionization chamber (IC) and MTS-N (LiF: Mg, Ti) chips when both detectors are exposed to $\leq 5 \mathrm{mGy}$ with a 10 by 10 field size, with an X-ray source and to determine the accuracy of the Thermoluminescent (TL) chips. Also, the dose will be compared to similar studies. 
Materials and Methods: A functional, Digital Radiography (DR) X-ray System was used. A DCT-100mm ionization chamber (IC) and an XR Multidetector was positioned at a Source to Image Distance (SID) of $100 \mathrm{~cm}$ on polystyrene, about $20 \mathrm{~cm}$ thick. An X-ray spectrum generated at a Practical Peak Voltage (PPV) of 60$107 \mathrm{kV}$ with Half Value Layer (HVL) of $2.4-4.3 \mathrm{mmAl}$ and filtration $>3 \mathrm{mmAl}$ was used. The same setup was used for the MTS-N chips.

Results: The mean doses for $1-5 \mathrm{mGy}$ with the MTS-N chips were $1.07 \pm 0.07$, $1.60 \pm 0.13,2.23 \pm 0.11,2.58 \pm 0.07$ and $3.45 \pm 0.10 \mathrm{mGy}$ respectively, with accuracies of $7,20,26,36$ and $31 \%$. Dose accuracy at 1 and $2 \mathrm{mGy}$ was within $25 \%$ respectively. Dose accuracies at 3,4 and $5 \mathrm{mGy}$ was within $>25 \%$. The correction factor for $1-5 \mathrm{mGy}$ was $0.94,1.25,1.35,1.55$ and 1.45 respectively.

Conclusion: Validation of the MTS-N chips with the reference ionization chamber to this study was within 36\%. The Radiation and Nuclear Safety Authority (STUK) recommends that ESAK be within 25\% for entrance surface dose. ESAK accuracy mostly increased with dose as observed in this study.

Keywords: Entrance surface air kerma, Backscatter radiation, Accuracy, Ionization chamber, Detector, MTS-N chips.

\section{Introduction}

Diagnostic medical exposure accounts for the largest use of ionizing radiation globally [1-3]. The cost of doing a routine X-ray examination is considered the cheapest, compared to other imaging modalities. Today, patient dosimetry plays an important role in dose optimization, intending to protect patients from an unusual high radiation dose [4-6]. Today in Nigeria, there is no patient dose audit in most diagnostic radiology facilities due to the lack of manpower (medical physicist) and dosimetric tools for dose assessment [7]. 
An important document titled dosimetry in diagnostic radiology: An international code of practice published by the International Atomic Energy Agency (IAEA), under the technical reports series no. 457 has been adopted as a guide in determining uncertainty associated with the use of thermoluminescent dosimeters (TLDs) and other dose indicators for patient dosimetry [8]. Materials like Lithium Fluoride ( $\mathrm{LiF}$ ) doped with Magnesium (Mg) and Titanium (Ti) are the most widely used for this purpose because of their density and tissueequivalent nature [9-11]. Most new radiographic systems, now come with parallel plate IC for dose measurements over a certain beam area, for patient dose assessment [12]. The energy response of TLDs particularly LiF: Mg, Ti have been studied for personal and patient dosimetry, with a minimum detectable dose of $0.01 \mathrm{mSv}[13,14]$.

The principal quantities for patient dosimetry in general radiography are the incident air kerma (iAK), the entrance surface air kerma (ESAK) and the air kerma-area product (AKAP). One or more of these quantities may be determined depending upon user requirements. The ESAK measurement can be done indirectly or directly. The indirect method requires no patient but the direct method requires the presence of a patient. In either case, TLDs have the advantage of being physically small, enabling them to be placed or attached to the body of the patient with ease, with very little interference in patient mobility or comfort and they are unlikely to obscure useful diagnostic information. Direct dose measurements during the course of real examinations on real patients provide the best indication of actual clinical practice $[15,16]$.

This study used MTS-N (LiF: Mg, Ti) chips. General use of TLDs requires that they are first annealed to erase residual energy using an annealing oven at known temperatures, after which they are exposed to ionizing radiation before they are read using a TLD reader. Usually, the measurement chamber of the reader contains a PMT Tube module, a heating unit, an exchangeable filter unit and a nitrogen gas supply unit. Once the element is heated through the heating unit, trapped energy is released in the form of light, from which a Photo Multiplier Tube (PMT) does the light amplification before it is converted into an electrical signal [17]. 
In a facility where MTS-N chips are newly available for patient dose audit, the accuracy of these chips is of great concern to avoid dose errors; hence, the purpose of this study was to compare the mean ESAK between a DCT-100mm Ionization Chamber (IC), which will serve as our reference instrument and MTS-N (LiF: Mg, Ti) chips. Both detectors will be exposed to 1, 2, 3, 4 and 5mGy respectively, under the same condition to determine the accuracy that exists between both devices.

\section{Materials and methods}

A Digital X-ray unit with acceptable exposure reproducibility was used. The calibrated DCT-100mm Ionization Chamber (IBA Dosimetry, Germany) was used alongside a MagicMax basic unit, which can measure doses (in $\mu \mathrm{Gy}$, mGy and Gy) and other quantities like the dose rate and exposure time simultaneously. The IC was carefully placed on a rectangular polystyrene material. It was positioned at a Source to Image Distance (SID) of $100 \mathrm{~cm}$, covering a beam area of 10 by $10 \mathrm{~cm}^{2}$. These processes were used alongside the XR Multi-Detector, which is a semiconductor, which can measure the dose (mGy), Practical Peak Voltage (PPV), Half Value Layer (HVL) and beam filtration. Exposure was made within the range of $60-107 \mathrm{kV}$ to achieve $1-5 \mathrm{mGy}$. The range of HVL was $2.4-4.3 \mathrm{~mm}$, using the MagicMax XR detector (RQA-5). The same set-up as mentioned above was used for the pre-annealed MTS-N chips, with the size of $3.2 \mathrm{~mm} \times 3.2 \mathrm{~mm} \times 0.9 \mathrm{~mm}$ (Figure 1). A RadPro Cube 400 manual TLD Reader (Freiberg Instruments GmbH, Germany) was used to determine corresponding TL count for the chips. The average background count was obtained from several TL chips that were not exposed to radiation denoted as $\mathrm{TL}_{0}$. The obtained $\mathrm{TL}$ counts $\left(\mathrm{TL}_{\mathrm{i}}-\mathrm{TL}_{0}\right)$ were multiplied with a pre-determined X-ray calibration factor [18]. The equation was as follows [8]: 
$\operatorname{ESAK}=\left(\mathrm{TL}_{i}-\mathrm{TL}_{0}\right) \times \mathrm{CF}_{\mathrm{CS}-137}(\mathrm{mGy} /$ count $)$

Where $\mathrm{TL}_{\mathrm{i}}=1,2,3 \ldots$ is the count from the ten selected chips, $\mathrm{TL}_{0}$ is the background count, and CF is the Calibration Factor for Cesium-137 source. This study compared \% deviation between measured and actual ESAK. The percentage deviation and absolute error were given as:

$\%$ Deviation $=\frac{D_{\text {measured }}-D_{\text {actual }}}{D_{\text {actual }}}$

Where:

Dmeasured $=$ was the dose obtained with the MTS-N chips

Dactual $=$ was the dose obtained with the DCT-100mm Ionization Chamber

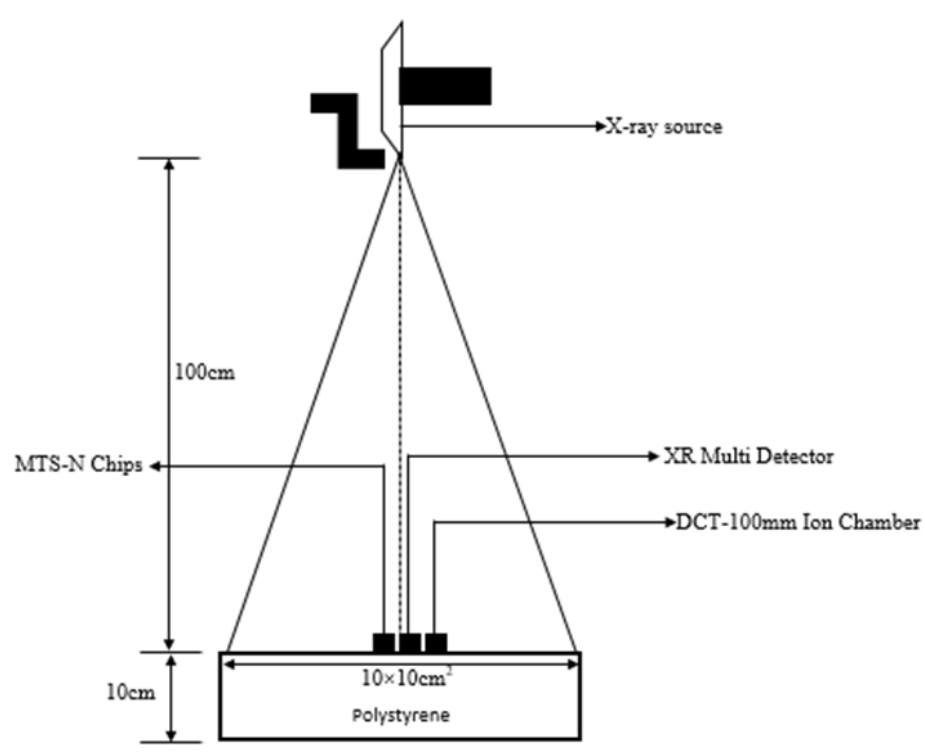

Figure 1. Setup for the measurement of ESAK with ionization chamber (the MTS-N chips were arranged in this manner and numbered serially). 


\section{Results}

The mean measured ESAK with the MTS-N chips at $1 \mathrm{mGy}$ was $1.07 \pm 0.07 \mathrm{mGy}$ with a deviation of $7 \%$. The $\%$ deviation of the individual MTS-N chips was 14,17 , $3,8,9,4,-5,16,6$ and -1 respectively, with the highest from the second TL chip. The absolute error (Ea) ranged from 0.01-0.17 (Table 1).

Table 1. Comparison of the actual and measured dose at $1 m G y$.

\begin{tabular}{cccc}
\hline No of chips & Measured dose $(\mathrm{mGy})$ & Actual dose $(\mathrm{mGy})$ & Absolute error (Ea) \\
\hline 1 & 1.14 & 1 & 0.14 \\
2 & 1.17 & 1 & 0.17 \\
3 & 1.03 & 1 & 0.03 \\
4 & 1.08 & 1 & 0.08 \\
5 & 1.09 & 1 & 0.09 \\
6 & 1.04 & 1 & 0.04 \\
7 & 0.95 & 1 & 0.05 \\
8 & 1.16 & 1 & 0.16 \\
9 & 1.06 & 1 & 0.06 \\
10 & 0.99 & 1 & 0.01 \\
\hline
\end{tabular}

Also, the mean measured ESAK with the MTS-N chips at 2mGy was $1.59 \pm$ $0.13 \mathrm{mGy}$ with a deviation of $20 \%$. The $\%$ deviation of the individual MTS-N chips was $-11.5,-24.5,-29,-13.5,-18.5,-27.5,-26,-12.5,-22$ and -20.5 respectively. The absolute error (Ea) ranged from $0.23-0.58$, with the highest deviation from the third chip (Table 2). 
Table 2. Comparison of the actual and measured dose at $2 m G y$.

\begin{tabular}{|cccc|}
\hline No of chips & Measured dose $(\mathrm{mGy})$ & Actual dose $(\mathrm{mGy})$ & Absolute error (Ea) \\
\hline 1 & 1.77 & 2 & 0.23 \\
\hline 2 & 1.51 & 2 & 0.49 \\
3 & 1.42 & 2 & 0.58 \\
\hline 4 & 1.73 & 2 & 0.27 \\
\hline 5 & 1.63 & 2 & 0.37 \\
\hline 6 & 1.45 & 2 & 0.55 \\
\hline 7 & 1.48 & 2 & 0.52 \\
\hline 8 & 1.75 & 2 & 0.25 \\
\hline 9 & 1.56 & 2 & 0.44 \\
\hline 10 & 1.59 & 2 & 0.41 \\
\hline
\end{tabular}

Furthermore, the mean measured dose with the MTS-N chips at 3mGy was 2.23 \pm $0.11 \mathrm{mGy}$ with a deviation of $26 \%$. The $\%$ deviation from individual MTS-N chips were $-25,-22,-31,-20,-28,-25,-31,-23,-26$ and -26 respectively. The absolute error (Ea) ranged from 0.61-0.94 (Table 3).

Table 3. Comparison of the actual and measured dose at $3 m G y$.

\begin{tabular}{|cccc|}
\hline No of chips & Measured dose $(\mathrm{mGy})$ & Actual dose $(\mathrm{mGy})$ & Absolute error (Ea) \\
\hline 1 & 2.25 & 3 & 0.75 \\
2 & 2.35 & 3 & 0.65 \\
3 & 2.06 & 3 & 0.94 \\
\hline 4 & 2.39 & 3 & 0.61 \\
\hline 5 & 2.16 & 3 & 0.84 \\
6 & 2.26 & 3 & 0.74 \\
\hline 7 & 2.08 & 3 & 0.92 \\
8 & 2.32 & 3 & 0.68 \\
9 & 2.22 & 3 & 0.78 \\
10 & 2.23 & 3 & 0.77 \\
\hline
\end{tabular}


Also, the mean measured dose with the MTS-N chips at $4 \mathrm{mGy}$ was $2.58 \pm 0.07 \mathrm{mGy}$ with a deviation of $36 \%$. The $\%$ deviation from individual MTS-N chips were -13 , $-17,-11,-14,-11,-10,-13,-12,-15$ and -9 respectively. The absolute error (Ea) ranged from $0.35-0.66$ (Table 4 ).

Table 4. Comparison of the actual and measured dose at $4 \mathrm{mGy}$.

\begin{tabular}{cccc}
\hline No of chips & Measured dose $(\mathrm{mGy})$ & Actual dose $(\mathrm{mGy})$ & Absolute error (Ea) \\
\hline 1 & 3.48 & 4 & 0.52 \\
2 & 3.34 & 4 & 0.66 \\
3 & 3.56 & 4 & 0.44 \\
4 & 3.46 & 4 & 0.54 \\
5 & 3.58 & 4 & 0.42 \\
6 & 3.6 & 4 & 0.40 \\
7 & 3.48 & 4 & 0.52 \\
8 & 3.52 & 4 & 0.48 \\
9 & 3.4 & 4 & 0.60 \\
10 & 3.65 & 4 & 0.35 \\
\hline
\end{tabular}

Finally, the overall average measured dose with the MTS-N chips at $5 \mathrm{mGy}$ was $3.45 \pm 0.10 \mathrm{mGy}$ with a deviation of $31 \%$. The $\%$ deviation from individual MTS-N chips were $-32.4,-32.2,-29.0,-32.6,-27.4,-28.4,-31.6,-32.4,-32.6$, and -30.6 respectively. The absolute error (Ea) ranged from 1.37-1.63 (Table 5). 
Table 5. Comparison of the actual and measured dose at $5 m G y$.

\begin{tabular}{|cccc|}
\hline No of chips & Measured dose $(\mathrm{mGy})$ & Actual dose $(\mathrm{mGy})$ & Absolute error (Ea) \\
\hline 1 & 3.38 & 5 & 1.62 \\
\hline 2 & 3.39 & 5 & 1.61 \\
\hline 3 & 3.55 & 5 & 1.45 \\
4 & 3.37 & 5 & 1.63 \\
\hline 5 & 3.63 & 5 & 1.37 \\
\hline 6 & 3.58 & 5 & 1.42 \\
\hline 7 & 3.42 & 5 & 1.58 \\
\hline 8 & 3.38 & 5 & 1.62 \\
\hline 9 & 3.37 & 5 & 1.63 \\
\hline 10 & 3.47 & 5 & 1.53 \\
\hline
\end{tabular}

\section{Discussion}

This study determined surface doses using an X-ray source in the range of 60$107 \mathrm{kV}$ from which $1-5 \mathrm{mGy}$ was achieved. Deviation in dose progressively increased from $1-3 \mathrm{mGy}$. Dose at $1 \mathrm{mGy}$ was the most accurate $(7 \%)$ due to the small influence of the backscatter radiation (BSR) compared to doses from 2-5mGy. The highest deviation was observed with $4 \mathrm{mGy}$, which was $36 \%$. Although correction factors were determined concerning the actual dose that was delivered, which ranged from $0.94-1.55$, the radiation and nuclear safety authority guideline (STUK) in Finland recommends that the entrance surface air kerma (ESAK) be within $\pm 25 \%$. Compared with our study, it shows that only 1 and $2 \mathrm{mGy}$ were within the recommended limit. We observed that the ESAK from the IC may increase, due to the influence of scatter radiation as a result of the size and shape of the chamber relative to the ESAK from the TL chips, thereby by increasing the deviation. The latter may be prominent as dose increases (3-5mGy).

A study by Nilsson and Sorcini also reported the use of some correction factors of $0.82,0.90$ and 1.00 using a Cobalt-60 source with 6 and 21-MV in a study to determine surface dose measurements in clinical photon beams with TLDs [20]. 
Furthermore, a study by Yuosof et al, who compared the variation in dose between ionization chamber and TLD-100 shows that at 81 and $125 \mathrm{kV}$, \% deviation between the ionization and TLD-100 were 48 and 34\% respectively. Similarly, with 6 and 10MV, \% deviation was 19 and 18\% respectively. The obtained results from their study for X-ray energy were similar to what we obtained for $60-107 \mathrm{kV}$, which was $\pm 36 \%$. The latter shows that at higher energies (radiotherapy range), better stability was observed [21].

High deviations at low doses using different types of TLDs have been reported. For instance, an investigation to the effect of TLD-700 energy response at low energy X-ray encountered in diagnostic radiology using caesium-137 source by Herrati et al, shows that maximum deviation could reach $60 \%$ and his study also shows that with the use of appropriate radiation quality (RQR5), dose accuracy can be reduced by up to $20 \%$ [22]. Alashrah et al in his study also reported a deviation up to $50 \%$ at the surface of a water phantom at a depth of $0.007 \mathrm{~cm}$ as recommended by the International Commission on Radiological Protection (ICRP) and the International Commission on Radiation Units and Measurement (ICRU) with radiochromic films (RFs), thermoluminescent dosimeters and an ionization chamber with a 6-MV photon beam [23]. A study by Reynolds et al, who investigated surface dose using a $6 \mathrm{MV}$ X-ray beam shows a deviation of 27.72 and 41.92 with TLD and optically stimulated dosimeter (OSLD) for uncorrected doses [24]. Comparison of dosimeter response of the ionization chamber, TLD, and Gafchromic EBT2 film from a study by Fitriandini et al, shows that the accuracy associated with the use of TLD was $-13.3 \%$ for surface dose in 3D-CRT, IMRT and SBRT. The maximum deviation in this study was $\pm 36 \%$, [25].

Some other studies determined doses at certain depths. A study by Waqar et al reported an accuracy that was within 5\% for a dose range of 250-5000mGy at a depth of $5 \mathrm{~cm}$ [26], while Lee et al reported accuracy of 3\% [27]. Measurement at a certain depth has been shown to deviate less compared to what was obtained in our study for entrance surface doses. As discussed above, a correction factor is often applied to compensate for this error. 


\section{Conclusion}

A comparison of mean ESAK between IC and MTS-N chips using kilovoltage X-ray source was determined. The maximum deviation from the study was $\pm 36 \%$. Better accuracy was obtained at a relatively lower dose ( 1 and $2 \mathrm{mGy}$ ), which was within $\pm 25 \%$ as recommended in the Radiation and Nuclear Safety Authority (STUK); Helsinki, Finland, report for entrance surface dose. The determined correction factors show that there exist uncertainties, which may have affected measurements considering the size and shape of the detectors used. The study proves useful for patient dosimetry and will serve as a guide in diagnostic radiology.

\section{Limitation of the study}

1. The shape and thickness of the IC and the XR multi-detector may have increased scatter radiation compared to the MTS-N chip, which is relatively small.

2. Uncertainties arising from the TL chip was not factored in our calculations, which may have affected the accuracy of our results. 


\section{References}

1. Do KH. General principles of radiation protection in fields of diagnostic medical exposure. J Korean Med Sci 2016;31 Suppl 1 :S6-9. doi: 10.3346/ jkms.2016.31.S1.S6.

2. Awosan KJ, Ibrahim M, Saidu SA, Ma'aji SM, Danfulani M, Yunusa EU, et al. Knowledge of radiation hazards, radiation protection practices and clinical profile of health workers in a teaching hospital in Northern Nigeria. J Clin Diagn Res 2016; 10(8): LC07-12. doi: 10.7860/JCDR/2016/20398.8394.

3. Mettler FA Jr, Thomadsen BR, Bhargavan M, Gilley DB, Gray JE, Lipoti JA, et al. Medical radiation exposure in the U.S. in 2006: preliminary results. Health Phys 2008; 95: 502-7. doi: 10.1097/01.HP.0000326333.42287.a2.

4. Sistrom CL, McKay NL. Costs, charges, and revenues for hospital diagnostic imaging procedures: differences by modality and hospital characteristics. J Am Coll Radiol 2005;2:511-9. doi: 10.1016/j.jacr.2004.09.013.

5. Bercovich E, Javitt MC. Medical imaging: from roentgen to the digital revolution, and beyond. Rambam Maimonides Med J 2018;9(4):e0034. doi: 10.5041/RMMJ.10355.

6. Howell JD. Early clinical use of the X-ray. Trans Am Clin Climatol Assoc 2016; 127:341-9.

7. Obed RI, Ekpo ME, Omojola AD, Abdulkadir MK. Medical physics professional development and education in Nigeria. Med Phys Int 2016;4: 96-8.

8. International Atomic Energy Agency,Dosimetry in diagnostic radiology: an international code of practice. Vienna: IAEA; 2007. Technical Reports Series No.: 457. 
9. Horowitz YS, Satinger D, Fuks E, Oster L, Podpalov L. On the use of LiF:Mg,Ti thermoluminescence dosimeters in space-a critical review. Radiat Prot Dosimetry 2003; 106:7-24. doi: 10.1093/oxfordjournals.rpd.a006337.

10. Sadeghi M, Sina S, Faghihi R. Investigation of LiF, Mg and Ti (TLD-100) reproducibility. J Biomed Phys Eng 2015;5:217-22.

11. Horowitz Y, Oster L, Eliyahu I. Review of dose-rate effects in the thermoluminescence of LiF: Mg, Ti (HARSHAW). Radiat Prot Dosimetry 2018;179:184-8. doi: 10.1093/rpd/ncx248.

12. Hasegawa H, Sato M, Tanaka H. Evaluation of an X-Ray dose profile derived from an optically stimulated luminescent dosimeter during Computed Tomographic Fluoroscopy. PLoS ONE 2015;10(7):e0132154. doi: 10.1371/ journal.pone.0132154.

13. Choi Y, Shil Cha E, Jin Bang Y, Ko S, Ha M, Lee C, et al. Estimation of organ doses among diagnostic medical radiation workers in South Korea. Radiat Prot Dosimetry 2018;179:142-50. doi: 10.1093/rpd/ncx239.

14. Ivanauskaite D, Griciene B. Status of individual dosimetry for dentists in Lithuania in year 1996-2001. Stomatologija 2003;5:149-51.

15. Sharma J, Sarma J, Agarwal S. Assessment of diagnostic reference level in radiography of neonatal chest anteroposterior examination: a hospital-based study. J Med Phys 2018;43:200-3. doi: 10.4103/jmp.JMP_37_18.

16. Institute of Physical Sciences in Medicine. National protocol for patient dose measurement in diagnostic radiology. Chilton:NRPB;1992.

17. Raffi RA, Davis SD, Hammer CG, Micka JA, Kunugi KA, Musgrove JE; et al. Determination of exit skin dose for 192Ir intracavitary accelerated partial breast irradiation with thermoluminescent dosimeters. Med Phys 2010;37: 2693-702. doi: 10.1118/1.3429089. 
18. Omojola AD, Akpochafor MO, Adeneye SO, Aweda MA. Calibration of MTS $\mathrm{N}$ (LiF: Mg, Ti) chips using cesium 137 source at low doses for personnel dosimetry in diagnostic radiology. Radiat Prot Environ 2020;43:108-14.

19. Radiation and Nuclear Safety Authority (STUK). Radiation practices and radiation measurements. Helsinki: STUK; 2016.

20. Nilsson B, Sorcini B. Surface dose measurements in clinical photon beams. Acta Oncol 1989;28:537-42. doi: 10.3109/02841868909092265.

21. Yusof MFM, Yahya MH, Rosnan MS, Abdullah R, Abdul Kadir AB. Dose measurement using $\mathrm{Al} 2 \mathrm{O} 3$ dosimeter in comparison to $\mathrm{LiF}: \mathrm{Mg}, \mathrm{Ti}$ dosimeter and ionization chamber at low and high energy X-ray. AIP Conf Proc 2017;1799:040007.doi: 10.1063/1.4972931.

22. Herrati A, Bourouina $M$, Khalal-Kouache K. Investigation of TLD-700 energy response to low energy $\mathrm{x}$-ray encountered in diagnostic radiology. Open Phys 2016;14:150-8. doi: 10.1515/phys-2016-0016.

23. Alashrah S, Kandaiya S, Maalej N, El-Taher A. Skin dose measurements using radiochromic films, TLDs and ionisation chamber and comparison with Monte Carlo simulation. Radiat Prot Dosimetry 2014;162:338-44. doi: $10.1093 / \mathrm{rpd} / \mathrm{nct} 315$.

24. Reynolds TA, Higgins P. Surface dose measurements with commonly used detectors: a consistent thickness correction method. J Appl Clin Med Phys 2015;16:358-66. doi: 10.1120/jacmp.v16i5.5572.

25. Fitriandini A, Wibowo WE, Pawiro SA. Comparison of dosimeter response: ionization chamber, TLD, and Gafchromic EBT2 film in 3D-CRT, IMRT, and SBRT techniques for lung cancer. J Phys:Conf Ser 2016;694:012006. doi: 10.1088/1742-6596/694/1/012006. 
26. Waqar M, Ul-Haq A, Bilal S, Mosood M. Comparison of dosimeter response of TLD-100 and ionization chamber for high energy photon beams at KIRAN Karachi in Pakistan. Egypt J Radiol Nucl Med 2017; 48 :479-83. doi:10.1016/j. ejrnm.2017.01.012

27. Lee JH, Chang LT, Shiau AC, Chen CW, Liao YJ, Li WJ,et al. A novel simple phantom for verifying the dose of radiation therapy. BioMed Res Int 2015 ;2015:934387. doi: 10.1155/2015/934387. 